\title{
Catecholamine-Mediated Reduction in Uterine Blood Flow after Nicotine Infusion in the Pregnant Ewe
}

\author{
Robert Resnik, Gary W. Brink, and Mahlon Wilkes, Department of Reproductive \\ Medicine, University of California, San Diego, School of Medicine, La Jolla, \\ California 92093
}

A B S T R A C T The effect of nicotine on uterine blood flow, uterine vascular resistance, and plasma catecholamine concentration was studied in chronically catheterized pregnant sheep equipped with electromagnetic flow probes. The systemic administration of nicotine (14-32 $\mu \mathrm{g} / \mathrm{kg}$ body wt per min) resulted in a $44 \%$ reduction in uterine blood flow $(P<0.001)$ and a $203 \%$ increase in uterine vascular resistance. Both responses were inhibited by pretreatment with the alpha blocker, phentolamine. Arterial plasma concentrations of norepinephrine and epinephrine, measured by a single isotopic radioenzymatic assay, rose (from $117.9 \pm 6.7$ to $201.8 \pm 13.3 \mathrm{pg} / \mathrm{ml}, P<0.001$; and from $71.6 \pm 4.5$ to $124.1 \pm 8.4 \mathrm{pg} / \mathrm{ml}, P<0.001$, respectively) during nicotine infusion. The findings suggest that nicotine exerts a deleterious effect on uterine blood flow mediated through the release of catecholamines.

\section{INTRODUCTION}

Smoking during pregnancy appears to be associated with a less than optimal fetal outcome. The spectrum of complications includes low birth weight infants (1-7), abortion $(1,3,4)$, prematurity (6), and an increase in perinatal mortality rate $(6,8,9)$. There is also data that suggests that subsequent intellectual development of children is impaired (10). These numerous clinical effects of maternal smoking have recently been reviewed by Pirani (11).

Abundant evidence, summarized by Longo (12), suggests that carbon monoxide in cigarette smoke may be the responsible factor, at least in part, for the observed deleterious fetal effects. However, the psychologic consequences of nicotine on the uterine vasculature have not been clearly defined. Nicotine is known to activate the adrenergic system through sympathetic ganglia and by the release of catecholamines

\footnotetext{
Address reprint requests to Dr. Robert Resnik.

Received for publication 21 November 1978 and in revised form 26 January 1979.
}

from the adrenal medulla. As a result of the nicotineinduced catecholamine release, it seems plausible that nicotine may impair fetal cardiovascular homeostasis by producing uterine vasoconstriction. To test this hypothesis, we studied the effects of nicotine infusion on uterine blood flow, uterine vascular resistance, and plasma catecholamines in chronically instrumented pregnant ewes.

\section{METHODS}

Cross-bred pregnant ewes were used during the investigation. The surgical procedure has been described in detail in previous reports $(13,14)$. After sedation with intravenous pentobarbitol sodium, $640 \mathrm{mg}$, a spinal anesthetic (Pontocaine hydrochloride, $6 \mathrm{mg}$; Winthrop Laboratories, New York) was administered. Pelvic laparotomy was performed through a midline incision. The anterior leaves of the broad ligament were incised, exposing the uterine arteries and their branches. The most lateral branch of each uterine artery was catheterized with polyvinyl tubing (i.d., $0.58 \mathrm{~mm}$; o.d., $0.96 \mathrm{~mm}$ ), and the catheter was advanced to within $0.5 \mathrm{~cm}$ of the bifurcation. 4- or 5-mm electromagnetic flow probes (Micron Instruments Inc., Los Angeles, Calif.) were placed around each uterine artery proximal to the bifurcation. Catheterization of the main uterine vein was accomplished by retrograde insertion through peripheral venous branches. Aortic and inferior vena cava catheters were placed via retrograde insertion through the femoral artery and vein. The catheters and flow probes were brought through a fascial incision and a subcutaneous tunnel, and then stored in a canvas pouch on the animal's flank.

After surgery, the ewe was placed in a rectangular stainless steel stall and remained in the laboratory for the duration of the studies. All studies were performed after the fifth postoperative day with the animal standing in its stall. Uterine arterial flow was measured with electromagnetic flow meters (Micron R.C. 1000, Micron Instruments, Inc.). Before daily experiments, the flow signals were internally calibrated to electrical zero. The signals were electronically integrated and displayed on a pen recorder (Gould Inc., Instruments Div., Cleveland, Ohio) running at the speed of $1 \mathrm{~mm} / \mathrm{min}$. Venous and arterial pressures were monitored with pressure transducers (Statham Instuments, Inc., Oxnard, Calif.).

32 hemodynamic experiments were performed in three ewes varying in gestational age from 109 to $144 \mathrm{~d}$. Nicotine (Eastman Organic Chemicals Div., Eastman Kodak Co., 
Rochester, N. Y.) was diluted in $0.9 \%$ saline to a concentration of $1 \mathrm{mg} / \mathrm{ml}$, and administered with a constant infusion pump (Harvard Apparatus Co., Inc., Millis, Mass.) into the inferior vena cava for $10 \mathrm{~min}$, at rates of $0.5,1.0$, or $1.5 \mathrm{mg} / \mathrm{min}$ (14-32 $\mu \mathrm{g} / \mathrm{kg}$ body wt per min). Arterial and uterine venous pressure measurements were recorded after identical nicotine infusions directly into one uterine artery. In five separate studies, nicotine infusion was preceeded by intravenous administration of an alpha blocker, phentolamine merylate, 3 mg (CIBA-Geigy Corp., Summit, N. J.), followed by a constant infusion of $2 \mathrm{mg}$ over $30 \mathrm{~min}$ during the nicotine injection period.

5-ml aliquots of uterine arterial or aortic blood were removed during the control and nicotine infusion periods for catecholamine determinations. Plasma norepinephrine and epinephrine were measured by a modified single isotopic radioenzymatic assay (15). Assay reagents in a volume of $0.17 \mathrm{ml}$ were mixed by $0.5-\mathrm{ml}$ plasma aliquots, such that the final incubation mixture contained $0.2 \mathrm{M}$ Tris, $30 \mathrm{mM} \mathrm{MgCl}$, $10 \mathrm{mM}$ EDTA, $0.1 \mathrm{mM}$ dithiothreitol, $0.4 \mathrm{mM} S$-adenosylmethionine (5-15 Ci/mmol from New England Nuclear, Boston, Mass.), $200 \mathrm{U} / \mathrm{ml}$ catechol-O-methyltransferase (Sigma Chemical Company, St. Louis, Mo.). The samples were incubated for $1 \mathrm{~h}$ at $37^{\circ} \mathrm{C}$. The reaction was stopped by addition of $0.5 \mathrm{ml}$ of $1 \mathrm{M} \mathrm{NaBO}_{3}(\mathrm{pH} \mathrm{11})$, and the radiolabeled catecholamines were extracted into $5 \mathrm{ml}$ of $\mathrm{H}_{2} \mathrm{O}$-saturated ethyl acetate:anisole $(10: 1)$. The methylated amines were back-extracted into $0.2 \mathrm{ml}$ of $0.1 \mathrm{~N} \mathrm{HCl}$ that contained $25 \mu \mathrm{g}$ each of 3-methoxytyramine, metanephrine, and normetanephrine as a cơld cartier. The samples were acetylated by addition of $0.1 \mathrm{ml}$ acetic anhydride, $0.2 \mathrm{ml} \mathrm{H}_{2} \mathrm{O}$, and $220 \mathrm{mg}$ of solid $\mathrm{NaHCO}_{3}$. The acetylated methoxyamines were extracted into $2 \mathrm{ml}$ of $\mathrm{H}_{2} \mathrm{O}$-saturated ethyl acetate, evaporated to dryness and redissolved in $\cong 0.08 \mathrm{ml}$ of $\mathrm{H}_{2} \mathrm{O}$-saturated ethyl acetate. The samples were subjected to one-dimensional thin layer chromatography with cyclohexane:chloroform:methanol: acetic acid (15:25:4:1) as the developing solvent. The spots corresponding to each catecholamine were cut into scintillation vials and counted. The sensitivity of this assay system is 4-20 $\mathrm{pg} / \mathrm{ml}$. The assay is linear $(r=0.999)$ for the catecholamines to at least $1 \mathrm{ng}$. The respective intra-assay variations for norepineprine and epinephrine are 4.5 and $5.9 \%$. The interassay variations are 12.8 and $14.9 \%$, respectively.

Blood flow data from individual animals were analyzed by Student's $t$ test. The combined data from all three animals were analyzed by analysis of variance.

\section{RESULTS}

Effects of systemic maternal nicotine infusions. Nicotine infusion of $1.0-1.5 \mathrm{mg} / \mathrm{min}$ into the inferior vena cava resulted immediately in a slight increase in uterine blood flow, followed promptly by a reduction in flow, which occurred within 5 min of the onset of the infusion. Flows returned to base-line levels by 15 min after termination of the nicotine infusion (Fig. 1). The mean magnitude of this change in the 32 flow experiments was a $44 \%$ decrease from base-line levels. The data from the individual ewes is shown in Fig. 2. No significant decrease in uterine blood flow occurred after doses of $0.5 \mathrm{mg} / \mathrm{min}$, and there were no statistically significant differences in the changes observed between doses of 1.0 and $1.5 \mathrm{mg} / \mathrm{min}$. The data demonstrating changes in uterine vascular resistance

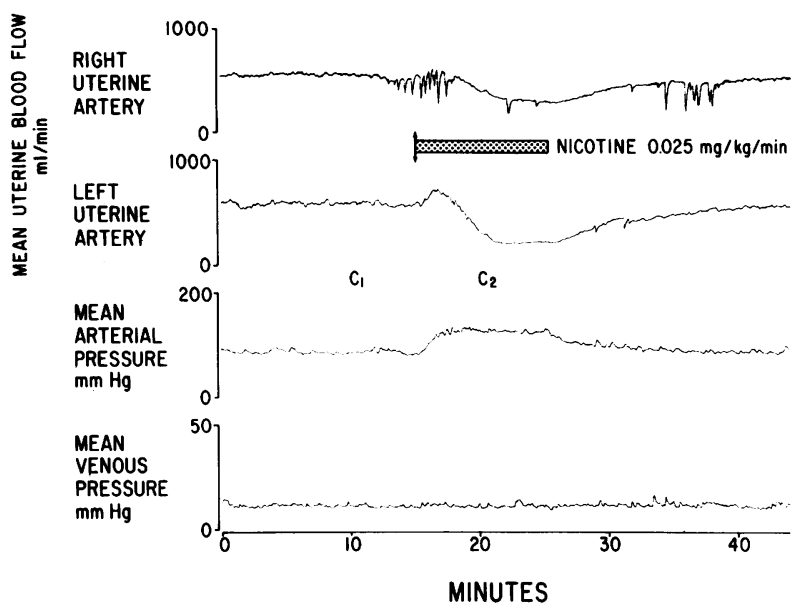

FIGURE 1 Uterine blood flow and arterial pressure responses after infusion of nicotine into the inferior vena cava in a single representative experiment.

are shown in Fig. 3. Uterine vascular resistance was measured during 13 flow experiments before nicotine infusion and when uterine blood flow reached its lowest point. The value before infusion was mean, $0.072 \pm 0.005 \mathrm{~mm} \mathrm{Hg} / \mathrm{ml}$ per $\mathrm{min}$ (SE). During nicotine infusion, there was an increase to a mean, $0.22 \pm 0.04 \mathrm{~mm}$ $\mathrm{Hg} / \mathrm{ml}$ per $\min (\mathrm{SE})(P=<0.005)$. This represents a $203 \%$ increase in uterine vascular resistance.

Effects of direct uterine intra-arterial nicotine infusions. Unlike the response to systemic administration, nicotine infusion directly into the uterine artery produced no changes in uterine blood flow, suggesting that the vascular response was not caused by a direct effect of nicotine on the vessel. Additionally, phentolamine infusion alone had no effect on uterine blood
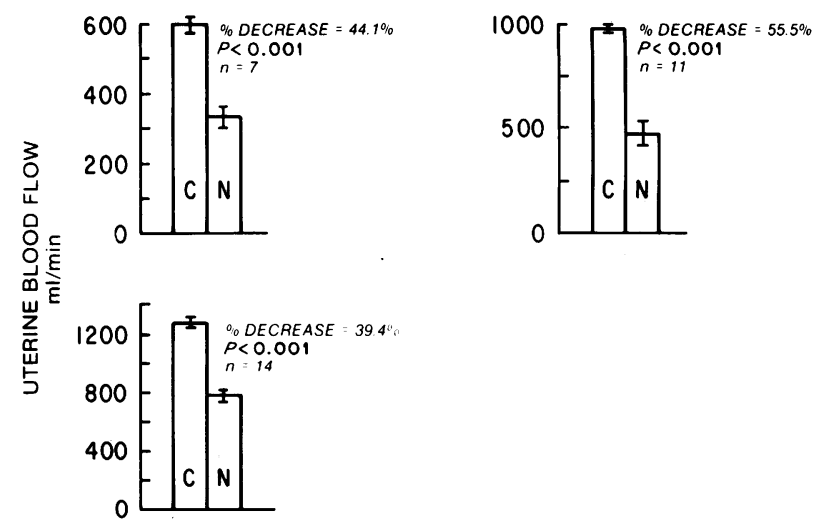

Figure 2 Comparison of uterine blood flow during the control period (C) compared to flows during nicotine infusion (N) in three animals. $n$ refers to the number of paired observations in each experiment. $P$ values indicate results of a Student's $t$ test. Analysis of variance of the combined data from all three ewes also discloses a significant effect of infusion of nicotine on uterine blood flow $(P<0.03)$. 


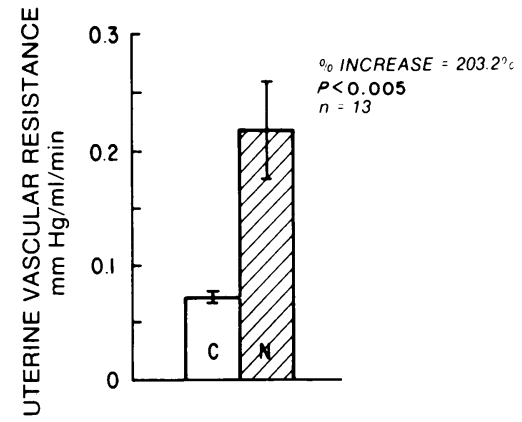

Figure 3 Uterine vascular resistance in the control period (C) compared to the nicotine infusion period (N) in 13 experiments.

flow, but did abolish the decrease in uterine blood flow resulting from the maternal systemic infusion of nicotine.

Plasma catecholamine responses to nicotine infusion. A marked increase in plasma catecholamine concentration was observed after systemic nicotine infusion. Arterial plasma norepinephrine levels rose from mean, $117.9 \pm 6.7 \mathrm{pg} / \mathrm{ml}(\mathrm{SE})$ in the control period to 201.8 $\pm 13.3 \mathrm{pg} / \mathrm{ml}$ (SE) during nicotine infusion $(P=<0.001)$, an increase of $70 \%$. Plasma epinephrine concentration increased from mean, $71.6 \pm 4.5 \mathrm{pg} / \mathrm{ml}$ to a mean, 124.1 $\pm 8.4 \mathrm{pg} / \mathrm{ml}$ after nicotine administration $(P=<0.001)$, an increase of $60 \%$. The pre- and postnicotine plasma catecholamine concentrations are summarized in Fig. 4. Direct uterine arterial infusions of nicotine, as well as intravenous saline administration, produced no significant increases in norepinephrine or epinephrine levels.

\section{DISCUSSION}

Presently, there is little information in the literature pertaining to the effects of nicotine on uterine blood flow. Kirschbaum et al. (16) were unable to demonstrate a nicotine-induced decrease in flow similar to that which we observed. However, their experiments were carried out on anesthetized animals with an exteriorized fetus, and the dose of nicotine was substantially less than that we recorded in our studies. More recently, acute experiments by Suzuki et al. ${ }^{1}$ have demonstrated a $38 \%$ decrease in uterine blood flow in pregnant monkeys after nicotine infusion, concomitant with fetal hypoxia. Our studies, in a chronic animal model, demonstrate that systemic nicotine infusions will consistently decrease uterine blood flow and increase uterine vascular resistance. The finding that direct uterine arterial infusions of nicotine have no effect on blood flow, combined with the observation that

\footnotetext{
${ }^{1}$ Suzuki, K., L. J. Minei, and E. E. Johnson. Manuscript in preparation.
}

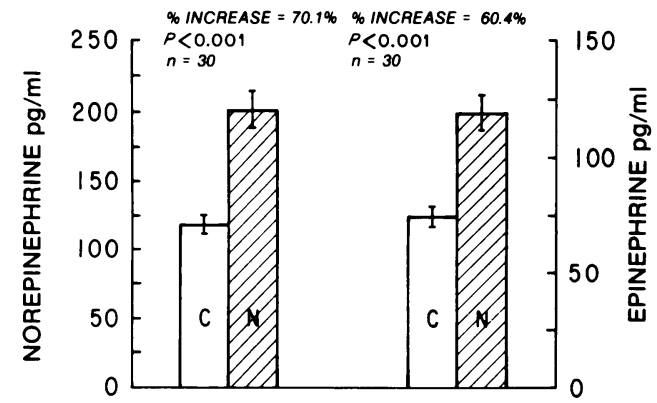

FIGURE 4 Plasma concentrations of norepinephrine and epinephrine in the control period $(\mathrm{C})$ and during nicotine infusion $(\mathrm{N})$.

pretreatment with the alpha blocker, phentolamine, inhibits the nicotine-induced response, strongly suggests that the nicotine response is mediated by the local and peripheral release of catecholamines.

Several investigators have shown that the sheep uterine vasculature is exquisitely sensitive to norepinephrine and epinephrine, and that the infusion of these agents will result in a decrease in uterine blood flow as well as redistribution of blood flow within the pregnant uterus (17-20). Barton et al. (18) reported that after exogenous adminstration of norepinephrine into the uterine artery of pregnant ewes, a calculated blood concentration of $2-3 \mathrm{ng} / \mathrm{ml}$ was required to decrease flow by $40 \%$. This concentration is considerably higher than that which we observed to produce a similar decrease, and is presumably a result of the fact that nicotine infusion releases large quantities of norepinephrine locally from adrenergic axon terminals, and that this may not be reflected in circulating levels of catecholamines.

It seems likely that nicotine may exert a deleterious fetal effect by a catecholamine-mediated reduction in utero-placental perfusion and consequent fetal oxygenation. In support of this hypothesis are the findings of Suzuki et al. (21) that maternal infusions of nicotine in acute monkey preparations are associated with fetal tachycardia, hypoxemia, and acidosis, in contrast to direct fetal infusions, which have no effect on acid-base balance. More recently, Manning et al. (22) observed transient fetal hypoxemia associated with a reduction in fetal breathing movements after nicotine infusions into chronically catheterized pregnant ewes. No significant changes in fetal blood gases were noted after nicotine was administered directly to the fetus. Also pertinent are the findings of Adamsons et al. (23), who observed fetal acidosis in monkeys after administration of catecholamines to the mother, but not the fetus.

The physiologic significance of these studies, in terms of their relevance to human pregnant smokers, remains a key issue. However, there are notable similarities between data obtained in sheep and human 
investigations. Quigley et al. ${ }^{2}$ have measured plasma catecholamines in our laboratory, obtained from pregnant women before and $7.5 \mathrm{~min}$ after initiation of cigarette smoking. The values they observed were similar to those we found before and after nicotine infusion in pregnant sheep, and are also in excellent agreement with those reported by Cryer et al. (24) in smoking men. There is also evidence to suggest that the dose of nicotine that we infused into sheep results in arterial concentrations compatible with those found in human cigarette smokers. Russell et al. (25) have shown that nicotine concentrations in humans who are moderate to heavy smokers range from 15 to $38 \mathrm{ng} / \mathrm{ml}$ 3 min after cigarette smoking. Utilizing nicotine doses in sheep similar to those we used in the present study, Manning et al. (22) observed arterial concentrations of nicotine almost identical to those found in human studies.

The effects of carbon monoxide on fetal oxygenation have been extensively described, and have been considered to constitute the predominant deleterious effect on the fetal environment. The data presented here strongly suggest that nicotine in tobacco smoke may play an additive role by decreasing uteroplacental perfusion through the local and peripheral release of catecholamines.

\section{ACKNOWLEDGMENT}

This investigation was supported by a grant from the National Foundation-March of Dimes and Rockefeller Foundation grant RF-75029.

\section{REFERENCES}

1. Lowe, C. R. 1959. Effect of mothers' smoking habits on birth weight of their children. Br. Med.J. 2: 673-676.

2. Simpson, W. J. 1957. A preliminary report on cigarette smoking and the incidence of prematurity. Am. J. Obstet. Gynecol. 73: 808-815.

3. Kline, J., A. Z. Stein, M. Susser, and D. Warburton. 1977. Smoking: a risk factor for spontaneous abortion. New Engl. J. Med. 297: 793-796.

4. Kullander, S., and B. Kallen. 1971. A prospective study of smoking and pregnancy. Acta Obstet. Gynecol. Scand. 50: 83-94.

5. Comstock, G. W., F. K. Shah, M. B. Meyer, and H. Abbey. 1971. Low birth weight and neonatal mortality rate related to maternal smoking and socioeconomic status. Am. J. Obstet. Gynecol. 111: 53-59.

6. Andrews, J., and J. M. McGarry. 1972. A community study of smoking in pregnancy. J. Obstet. Gynaecol. Br. Commonw. 79: 1057-1073.

7. Davies, D. P., and M. Abernathy. 1976. Cigarette smoking

${ }^{2}$ Quigley, M. E., K. L. Sheehan, M. M. Wilkes, and S. S. C. Yen. Manuscript in preparation. in pregnancy: Associations with maternal weight gain and fetal growth. Lancet. I: 383-387.

8. Meyer, M. B., J. A. Tonascia, and C. Buck. 1975. The interrelationship of maternal smoking and increased perinatal mortality with other risk factors. Further analysis of the Ontario perinatal mortality study, 1960-1961. Am. J. Epidemiol. 100: 443-452.

9. Meyer, M. B., and J. A. Tonascia. 1977. Maternal smoking, pregnancy complications and perinatal mortality. Am. J. Obstet. Gynecol. 128: 494-502.

10. Butler, N. R., and H. Goldstein. 1973. Smoking in pregnancy and subsequent child development. Br. Med.J. 4: 573-575.

11. Pirani, B. B. K. 1978. Smoking during pregnancy. Obstet. Gynecol. Surv. 33: 1-13.

12. Longo, L. D. 1977. The biological effects of carbon monoxide on the pregnant woman, fetus, and newborn infant. Am. J. Obstet. Gynecol. 129: 69-103.

13. Killam, A. P., C. R. Rosenfled, F. C. Battaglia, E. R. Makowski, and G. Meschia. 1973. The effect of estrogens on uterine blood flow. Am. J. Obstet. Gynecol. 115: 1045-1052.

14. Resnik, R., and G. W. Brink. 1978. Effects of prostaglandin $E_{1}, E_{2}$, and $F_{2 \alpha}$ on uterine blood flow in nonpregnant sheep. Am. J. Physiol. 234(5): H557-H561.

15. Parson, P. G., and J. D. Peuler. 1973. A simplified radiometric assay for plasma norepinephrine and epinephrine. Anal. Biochem. 51: 618-631.

16. Kirschbaum, T. H., P. V. Dilts, and C. R. Brinkman III. 1970. Some acute effects of smoking in sheep and their fetuses. Obstet. Gynecol. 35: 527-536.

17. Assali, N. S., L. W. Holm, and N. Sehgal. 1962. Regional blood flow and vascular resistance of the fetus in utero. Am. J. Obstet. Gynecol. 83: 809-817.

18. Barton, M. E., A. P. Killam, and G. Meschia. 1974. Response of ovine uterine blood flow to epinephrine and norepinephrine. Proc. Soc. Exp. Biol. Med. 145: 996- 1003.

19. Anderson, S. G., J. G. Still, and F. C. Griess. 1977. Differential reactivity of the gravid uterine vasculatures: effect of norepinephrine. Am. J. Obstet. Gynecol. 129: 293-297.

20. Rosenfeld, C. R. and J. West. 1977. Circulatory responses to systemic infusion of norepinephrine in the pregnant ewe. Am. J. Obstet. Gynecol. 127: 376-383.

21. Suzuki, K., T. Horiguchi, A. C. Comas-Urrutia, E. Mueller-Heubach, H. Morishima, and K. Adamsons. 1971. Pharmacologic effects of nicotine upon the fetus and mother in the rhesus monkey.Am.J. Obstet. Gynecol. 111: 1092-1101.

22. Manning, F., D. Walker, and C. Feyerabend. 1978. The effect of nicotine on fetal breathing movements in conscious pregnant ewes. Obstet. Gynecol. 52: 563-568.

23. Adamsons, K., E. Mueller-Heubach, and R. E. Myers. 1971. Production of fetal asphyxia in the rhesus monkey by administration of catecholamines to the mother. Am. J. Obstet. Gynecol. 109: 248-262.

24. Cryer, P. E., M. W. Haymond, J. V. Santiago, and S. D. Shah. 1976. Norepinephrine and epinephrine release and adrenergic mediation of smoking-associated hemodynamic and metabolic events. N. Engl. J. Med. 295: 573-577.

25. Russell, M. A. H., C. Wilson, V. A. Patel, C. Feyerabend, and P. V. Cole. 1975. Plasma nicotine levels after smoking cigarettes with high, medium, and low nicotine yields. Br. Med. J. 2: 414-416. 